BMJ Open

Diabetes

Research

\& Care

\section{Sitagliptin for the prevention of stress hyperglycemia in patients without diabetes undergoing coronary artery bypass graft (CABG) surgery}

To cite: Cardona S, Tsegka K, Pasquel FJ, et al. Sitagliptin for the prevention of stress hyperglycemia in patients without diabetes undergoing coronary artery bypass graft (CABG) surgery. BMJ Open Diab Res Care 2019;7:e000703. doi:10.1136/ bmjdrc-2019-000703

- Additional material is published online only. To view please visit the journal online (http://dx.doi.org/10.1136/ bmjdrc-2019-000703).

$\mathrm{SC}$ and $\mathrm{KT}$ contributed equally.

Partial data from this trial were presented at the American Diabetes Association meeting in June 2017.

Received 24 May 2019

Revised 18 July 2019

Accepted 17 August 2019

Check for updates

(C) Author(s) (or their employer(s)) 2019. Re-use permitted under CC BY-NC. No commercial re-use. See rights and permissions. Published by BMJ.

For numbered affiliations see end of article.

Correspondence to Professor Guillermo Umpierrez; geumpie@emory.edu

\section{ABSTRACT}

Aims To determine if treatment with sitagliptin, a dipeptidyl peptidase- 4 inhibitor, can prevent stress hyperglycemia in patients without diabetes undergoing coronary artery bypass graft (CABG) surgery.

Methods We conducted a pilot, double-blinded, placebocontrolled randomized trial in adults (18-80 years) without history of diabetes. Participants received sitagliptin or placebo once daily, starting the day prior to surgery and continued for up to 10 days. Primary outcome was differences in the frequency of stress hyperglycemia (blood glucose $(\mathrm{BG})>180 \mathrm{mg} / \mathrm{dL}$ ) after surgery among groups. Results We randomized 32 participants to receive sitagliptin and 28 to placebo (mean age $64 \pm 10$ years and $\mathrm{HbA1c:} 5.6 \% \pm 0.5 \%)$. Treatment with sitagliptin resulted in lower BG levels prior to surgery $(101 \pm \mathrm{mg} /$ $\mathrm{dL}$ vs $107 \pm 13 \mathrm{mg} / \mathrm{dL}, \mathrm{p}=0.01$ ); however, there were no differences in the mean $B G$ concentration, proportion of patients who developed stress hyperglycemia ( $21 \%$ vs $22 \%, p>0.99$ ), length of hospital stay, rate of perioperative complications and need for insulin therapy in the intensive care unit or during the hospital stay.

Conclusion The use of sitagliptin during the perioperative period did not prevent the development of stress hyperglycemia or need for insulin therapy in patients without diabetes undergoing CABG surgery.

\section{INTRODUCTION}

Stress hyperglycemia (blood glucose (BG) $>140 \mathrm{mg} / \mathrm{dL}$ ) is a common finding in patients with and without a history of diabetes (diabetes mellitus, DM) after cardiac surgery ${ }^{1}$ reported in $80 \%$ of patients with diabetes and in more than $50 \%$ of patients without history of diabetes after cardiac surgery. ${ }^{2}{ }^{3}$ Perioperative hyperglycemia in patients with and without DM is associated with higher perioperative mortality, ${ }^{4-6}$ deep sternal wound infections, ${ }^{78}$ acute renal failure, ${ }^{1}$ postoperative strokes, ${ }^{910}$ longer hospital stays, ${ }^{410}$ and higher healthcare resource utilization. ${ }^{11-13}$

In surgical patients, stress hyperglycemia has been arbitrarily defined as an increase

\section{Significance of this study}

What is already known about this subject?

- Stress hyperglycemia is very frequent in patients without diabetes undergoing coronary artery bypass graft (CABG).

What are the new findings?

- The use of sitagliptin in patients without diabetes undergoing $C A B G$ did not reduce the frequency of stress hyperglycemia in the intensive care unit (ICU), but was associated with lower insulin requirements during continuous insulin infusion in the ICU, and was safe and well tolerated in participants undergoing $\mathrm{CABG}$ surgery.

How might these results change the focus of research or clinical practice?

- We found minor differences in glucose levels before surgery and total insulin dose in the ICU among patients without diabetes exposed to sitagliptin. These differences, however, are unlikely to be clinically significant.

- Our preliminary results do not justify the conduction of a larger clinical trial in patients without diabetes.

in $\mathrm{BG}$ above $180 \mathrm{mg} / \mathrm{dL}$ in patients without previously diagnosed diabetes. ${ }^{14-16}$ Stress hyperglycemia results from the acute metabolic and hormonal changes associated with the response to injury, anesthesia, and stress. ${ }^{17}$ Although it has long been considered an adaptive stress response which is beneficial for survival, stress hyperglycemia is associated with a fourfold increased risk of complications compared with patients with normoglycemia and with a twofold higher complications compared with patients with a known history of diabetes. ${ }^{16} 18-22$

Clinical guidelines recommend the use of continuous intravenous insulin infusion (CII) for treatment of stress hyperglycemia 
in cardiac surgery patients. ${ }^{23-26}$ Although effective and widely utilized, ${ }^{27-29}$ the use of CII is labor intensive, requiring hourly BG testing and insulin drip adjustment, and is associated with a significant risk of hypoglycemia, reported in 5\%-32\% of patients in the intensive care unit (ICU).$^{30-33}$ Recently, we and others have reported that therapy with dipeptidyl peptidase-4 (DPP-4) inhibitors is an effective strategy to improve glycemic control in general medicine and surgical patients with type 2 diabetes with mild to moderate hyperglycemia (180$200 \mathrm{mg} / \mathrm{dL}){ }^{34}$ Therefore, we explored if the DPP-4 inhibitor sitagliptin, by stimulating insulin secretion in a glucose-dependent fashion and by reducing glucagon-mediated hepatic glucose production, could prevent the development of stress hyperglycemia during the perioperative period in cardiac surgery patients without a history of diabetes.

\section{SUBJECTS, MATERIALS, AND METHODS}

We performed a single-center, pilot, prospective, doubleblinded, randomized placebo-controlled study at four academic hospitals including Emory University Hospital, Emory Midtown Hospital, Emory Saint Joseph's, and Grady Memorial Hospital in Atlanta, Georgia, between January 2016 and October 2016.

\section{Patient and public involvement}

Patients were not invited to comment on the study design and were not consulted to develop patient-relevant outcomes or interpret the results. Patients were not invited to contribute to the writing or editing of this document for readability or accuracy.

We enrolled adult participants aged 18-80 years, without a history of diabetes, confirmed by $\mathrm{HbA1c}<6.5 \%$ (normal HbAlc <5.7\%, pre-diabetes: HbA1c 5.7\%-6.4\%; diabetes: $\mathrm{HbA1c} \geq 6.5 \%)^{35}$ and fasting $\mathrm{BG}<126 \mathrm{mg} / \mathrm{dL}$ obtained prior to hospital admission and/or surgery. We excluded patients with a history of diabetes or previous treatment with antidiabetic therapy, patients with decreased renal function (estimated glomerular filtration rate $(\mathrm{eGFR})<30 \mathrm{~mL} / \mathrm{min}$ per $1.73 \mathrm{~m}^{2}$ ) or with clinically significant liver disease, gastrointestinal (GI) obstruction or adynamic ileus, clinically relevant pancreatic or gall bladder disease or patients treated with oral or injectable corticosteroids.

Participants were randomly assigned to sitagliptin or matched placebo once daily. Research pharmacists at each institution received a computer-generated randomization table to assign participants (1:1) from a statistician. All medical and/or surgical management decisions were under the responsibility of the primacy care team.

The study drug, sitagliptin or placebo, was given once daily, starting the day prior to surgery and continued until hospital discharge, or up to 10 days. Sitagliptin dose was adjusted according to eGFR, per manufacturer instructions: $100 \mathrm{mg} /$ day if eGFR was $\geq 50 \mathrm{~mL} / \mathrm{min}$ per $1.73 \mathrm{~m}^{2}, 50 \mathrm{mg} /$ day if eGFR was $<50 \mathrm{~mL} / \mathrm{min}$ per $1.73 \mathrm{~m}^{2}$, and $25 \mathrm{mg}$ daily if the calculated GFR was $<30 \mathrm{~mL} /$ $\mathrm{min} / 1.73 \mathrm{~m}^{2}$ during the study period. BG was measured every $30 \mathrm{~min}$ intraoperatively, and every $1-2$ hours after arrival to ICU, until the patient was hemodynamically stable and could tolerate oral intake; at this point and after transition to regular floor, BG measurements were performed before each meal and at bedtime.

The primary outcome of the study was the difference in the frequency of stress hyperglycemia, defined as participants who had one or more episodes of BG $>180 \mathrm{mg} / \mathrm{dL}$, between participants treated with sitagliptin or placebo, after arrival to ICU. Secondary outcomes included differences in mean BG during the ICU stay, number of participants with persistent stress hyperglycemia after arrival to ICU, defined as two consecutive BG $>180 \mathrm{mg} / \mathrm{dL}$ or with average daily BG $>180 \mathrm{mg} / \mathrm{dL}$, need for CII in the ICU, mean insulin dose of CII and duration during ICU stay (unit/hour/day and units/day).

We also compared the frequency of stress hyperglycemia including BG $>140 \mathrm{mg} / \mathrm{dL}$ and $\mathrm{BG}>180 \mathrm{mg} / \mathrm{dL}$, mean daily $\mathrm{BG}$, and number of participants requiring subcutaneous insulin after transition from intravenous insulin, and number of participants with severe hyperglycemic events (BG $>200 \mathrm{mg} / \mathrm{dL}$ ) or with hypoglycemia (BG $\leq 70 \mathrm{mg} / \mathrm{dL}$ and $<40 \mathrm{mg} / \mathrm{dL}$ ). In addition, we explored differences in a composite of perioperative complications including sternal wound infection (deep and superficial), bacteremia, pneumonia (infection was confirmed by positive culture of blood, sputum, urine, pleural or mediastinal fluid, and/or incisional discharge), respiratory failure, acute kidney injury (serum creatinine increment level by $>50 \%$ from baseline), major adverse cardiovascular events including acute myocardial infarction, stroke, heart failure and cardiac arrhythmias (significant arrhythmias were those that caused hemodynamic instability and required treatment). Stroke was described as a neurological abnormality that was confirmed by a CT scan and/or neurologist. Additionally, we compared differences between groups in hospital-related outcomes, including: length of stay (LOS) in the ICU and the hospital, in-hospital mortality, hospital readmissions and emergency room visits within 30 days after hospital discharge.

Participants on arrival to ICU had point-of-care testing (POCT) BG checks every 1-2 hours according to institutional protocol, those who developed stress hyperglycemia continued to receive the study drug (sitagliptin or placebo) and were started on insulin regimen, adjusted to achieve and maintain a BG target between 110 and $180 \mathrm{mg} / \mathrm{dL}$ following our standard hospital protocol (see online supplementary appendix 1). ${ }^{36}$ Intravenous insulin was started with two values $>180 \mathrm{mg} / \mathrm{dL}$ in the ICU and continued until the patient was able to eat and/or transferred to non-ICU settings. Once patients tolerate oral intake, it is recommended that patients have POCT BG before each meal and at bedtime. After transition, participants with two consecutive BG $>180 \mathrm{mg} / \mathrm{dL}$, or with average daily $\mathrm{BG}>180 \mathrm{mg} / \mathrm{dL}$ received rescue therapy 
with subcutaneous basal (levemir or glargine) insulin once daily plus correction doses by sliding scale (see online supplementary appendix 2$).{ }^{37}$

\section{Statistical analysis}

This proof-of-concept proposal was a two-arm, randomized, placebo-controlled pilot clinical trial. In this pilot and proof-of-concept trial, we aimed to randomize a total of 60 patients scheduled to undergo cardiac surgery. Based on our recent GLUCO-CABG ${ }^{38}$ trial, $81 \%$ of participants without a history of diabetes had stress hyperglycemia (BG $>140 \mathrm{mg} / \mathrm{dL})$ and $69 \%$ had at least one BG $>180 \mathrm{mg} / \mathrm{dL}$. In the power calculation, we assumed the same rate of stress hyperglycemia in the control (placebo) group, and anticipated that sitagliptin would reduce the rate of hyperglycemia by $25 \%-50 \%$ (corresponding to OR in the range of $0.36-0.16)$. Under these assumptions, with the sample size of 60 (ie, 30 per group), we would have $92 \%, 80 \%$, and $41 \%$ power to detect effect sizes corresponding to $\mathrm{OR}=0.16,0.21$, and 0.36 , respectively. The preliminary effect estimates obtained in this pilot study would provide the data to consider the design of larger trials with realistic event rates and effect sizes.

The primary endpoint was the frequency of stress hyperglycemia $(>180 \mathrm{mg} / \mathrm{dL})$ after surgery. We first used two-sided $\chi^{2}$ test or Fisher's exact test to compare the rate of stress hyperglycemia and other categorical variables between the treatment group and the control group. We used non-parametric Kruskal-Wallis tests to compare continuous variables such as LOS or BG values. $\mathrm{P}$ values $<0.05$ are considered statistically significant. The data analyses were performed with SAS V.9.4.

\section{RESULTS}

Between January 2016 and October 2016, a total of 68 participants without history of diabetes signed the consent to participate in the study. Two participants were excluded because surgery was cancelled after percutaneous coronary intervention, four withdrew consent, one participant had the procedure rescheduled and did not receive study medication, and one participant was found to have a high HbA1c (see online supplementary appendix 3). A total of 60 participants completed enrollment and randomization, $32(53 \%)$ were assigned to the sitagliptin and 28 $(47 \%)$ were assigned to control (placebo) group. The clinical characteristics of study participants are shown in table 1. Groups were well matched at baseline, with no significant differences in age, gender, weight, body mass index, presence of comorbidities, type of surgery or American Society of Anesthesiologists status class (table 1). There were no differences in the mean glucose concentration at randomization (table 1), but those in the sitagliptin group had a slightly lower preoperative BG compared with placebo $101 \pm 18 \mathrm{mg} / \mathrm{dL}$ vs $107 \pm 13 \mathrm{mg} / \mathrm{dL}$, $\mathrm{p}=0.013$, respectively (table 2 ).

There were no differences in the primary endpoint, which was the frequency of stress hyperglycemia (BG
Table 1 Clinical characteristics on admission and glycemic control

\begin{tabular}{|c|c|c|c|}
\hline & Placebo & Sitagliptin & $P$ value \\
\hline Participants (n) & 28 & 32 & \\
\hline Gender & & & 0.55 \\
\hline Male, $\mathrm{n}$ & $23(82)$ & $24(75)$ & \\
\hline Age, years & $64 \pm 9$ & $64 \pm 11$ & 0.75 \\
\hline Race & & & 0.78 \\
\hline Caucasian & $20(71)$ & $20(63)$ & \\
\hline African-American & $6(21)$ & $9(28)$ & \\
\hline Other & $2(7)$ & $3(9)$ & \\
\hline Body weight, $\mathrm{kg}$ & $87 \pm 18$ & $84 \pm 17$ & 0.58 \\
\hline BMI, $\mathrm{kg} / \mathrm{m}^{2}$ & $28 \pm 6$ & $28 \pm 6$ & 0.77 \\
\hline \multicolumn{4}{|l|}{ Medical history } \\
\hline Dyslipidemia & $20(74)$ & $25(78)$ & 0.77 \\
\hline Hypertension & $22(79)$ & $27(84)$ & 0.74 \\
\hline Previous cardiac intervention & $10(36)$ & $14(44)$ & 0.60 \\
\hline Current smoker & $9(32)$ & $6(19)$ & 0.37 \\
\hline Surgery & & & 0.19 \\
\hline Elective/outpatient & $10(36)$ & $19(59)$ & \\
\hline Emergent & $1(4)$ & $2(6)$ & \\
\hline $\begin{array}{l}\text { Transfer from another } \\
\text { hospital }\end{array}$ & $5(18)$ & $2(6)$ & \\
\hline Urgent & $12(43)$ & $9(28)$ & \\
\hline \multicolumn{4}{|l|}{ Type of surgery } \\
\hline Primary isolated CABG & $23(82)$ & $25(78)$ & 0.76 \\
\hline CABG+valve repair & $3(11)$ & $5(16)$ & 0.71 \\
\hline Previous CABG & $3(11)$ & $2(6)$ & 0.65 \\
\hline Open CABG & $24(86)$ & $27(84)$ & $>0.99$ \\
\hline Robotic CABG & $3(11)$ & $5(16)$ & 0.71 \\
\hline On pump & $18(75)$ & $24(89)$ & 0.28 \\
\hline ASA & & & $>0.99$ \\
\hline III & $5(18)$ & $6(19)$ & \\
\hline IV & $23(82)$ & $25(78)$ & \\
\hline V & 0 & $1(3)$ & \\
\hline
\end{tabular}

Data are $\mathrm{n}(\%)$; mean \pm SD.

ASA, American Society of Anesthesiologists;BMI, body mass index; $\mathrm{CABG}$, coronary artery bypass graft surgery.

$>180 \mathrm{mg} / \mathrm{dL}$ ) during the operative period in participants treated with sitagliptin or placebo ( $38 \%$ vs $29 \%$, $\mathrm{p}=0.59$ ). We also explored differences in the proportion of participants with BG $>140 \mathrm{mg} / \mathrm{dL}$, which was also not significantly different between groups in all hospital settings (intraoperative: $75 \%$ vs $79 \%$, ICU: $84 \%$ vs $82 \%$, post-transition: $77 \%$ vs $69 \%$, $\mathrm{p}=\mathrm{NS}$ ). While in the ICU, the number of participants who developed stress hyperglycemia ( $\geq 2 \mathrm{BG}$ values $>180 \mathrm{mg} / \mathrm{dL}$ ) and required intravenous insulin therapy was similar in both groups $(22 \%$ vs $25 \%, \mathrm{p}>0.99)$. However, participants treated with sitagliptin required significantly lower total insulin dose during their first 48 hours in the ICU stay, compared with placebo $(37 \pm 60 \mathrm{IU} /$ day vs $83 \pm 64 \mathrm{IU} /$ day, $\mathrm{p}=0.035)$ 
Table 2 Glycemic control, insulin therapy and hospital complications

\begin{tabular}{|c|c|c|c|}
\hline & Placebo & Sitagliptin & $P$ value \\
\hline \multicolumn{4}{|l|}{ Glycemic control } \\
\hline Admission HbA1c, \% & $5.6 \pm 0.5$ & $5.6 \pm 0.4$ & 0.56 \\
\hline Randomization BG, mg/dL & $106 \pm 13$ & $100 \pm 18$ & 0.17 \\
\hline Preoperative BG, mg/dL & $107 \pm 13$ & $101 \pm 18$ & 0.013 \\
\hline $\mathrm{BG}$ during surgery, mg/dL & $143 \pm 18$ & $136 \pm 25$ & 0.21 \\
\hline BG during ICU stay, mg/dL & $138 \pm 25$ & $137 \pm 16$ & 0.78 \\
\hline $\mathrm{BG}$ after transition, mg/dL & $124 \pm 16$ & $123 \pm 13$ & 0.75 \\
\hline \multicolumn{4}{|l|}{ Hyperglycemia BG >140 mg/dL $(>7.8 \mathrm{mM})$} \\
\hline Participants with $B G>140 \mathrm{mg} / \mathrm{dL}$ in $\mathrm{OR}$ & $22(79)$ & $24(75)$ & 0.77 \\
\hline Participants with $B G>140 \mathrm{mg} / \mathrm{dL}$ in ICU & $23(82)$ & $27(84)$ & $>0.99$ \\
\hline Participants with $B G>140 \mathrm{mg} / \mathrm{dL}$ after transition & $18(69)$ & $24(77)$ & 0.55 \\
\hline \multicolumn{4}{|l|}{ Hyperglycemia $B G>180 \mathrm{mg} / \mathrm{dL}(>10.0 \mathrm{mM})$} \\
\hline Participants with $B G>180 \mathrm{mg} / \mathrm{dL}$ in $O R$ & $8(29)$ & $12(38)$ & 0.59 \\
\hline Participants with $>2 \mathrm{BG}>180 \mathrm{mg} / \mathrm{dL}$ during Cll & $6(21)$ & $7(22)$ & $>0.99$ \\
\hline Participants with $B G>180 \mathrm{mg} / \mathrm{dL}$ after transition & $8(31)$ & $8(26)$ & 0.77 \\
\hline \multicolumn{4}{|l|}{ Hyperglycemia BG >200 mg/dL (>11.1 mM) } \\
\hline Participants with $B G>200 \mathrm{mg} / \mathrm{dL}$ in OR & $3(11)$ & $3(9)$ & $>0.99$ \\
\hline Participants with $B G>200 \mathrm{mg} / \mathrm{dL}$ in ICU & $4(14)$ & $8(25)$ & 0.35 \\
\hline Participants with $B G>200 \mathrm{mg} / \mathrm{dL}$ after transition & $2(8)$ & $5(16)$ & 0.44 \\
\hline \multicolumn{4}{|l|}{ Hypoglycemia BG $<70$ mg/dL $(<3.9 \mathrm{mM})$} \\
\hline Participants with hypoglycemia during ICU & $1(4)$ & $2(6)$ & $>0.99$ \\
\hline Participants with hypoglycemia after transition & 0 & $1(3)$ & $>0.99$ \\
\hline \multicolumn{4}{|l|}{ Hypoglycemia BG $<40 \mathrm{mg} / \mathrm{dL}(<2.2 \mathrm{mM})$} \\
\hline Participants with $B G<40 \mathrm{mg} / \mathrm{dL}$ (all settings) & 0 & 0 & - \\
\hline Perioperative steroid administration & $8(29)$ & $5(16)$ & 0.35 \\
\hline Number of BG readings in ICU & $11.7 \pm 7.3$ & $15.4 \pm 18.1$ & 0.67 \\
\hline Number of $B G$ readings after transition & $20.4 \pm 8.5$ & $20.0 \pm 11.2$ & 0.51 \\
\hline \multicolumn{4}{|l|}{ Insulin therapy } \\
\hline Participants treated with Cll & $7(25)$ & $7(22)$ & $>0.99$ \\
\hline Duration of Cll, hours & $17(9,80)$ & $12(5,88)$ & 0.57 \\
\hline Total insulin dose in the ICU (first 48 hours), units & $83 \pm 64$ & $37 \pm 60$ & 0.035 \\
\hline Participants treated with subcutaneous SSI after transition & $5(18)$ & $5(16)$ & $>0.99$ \\
\hline Subcutaneous insulin required, units & $2.4 \pm 0.9$ & $2.4 \pm 0.5$ & 0.7 \\
\hline ICU LOS post-CABG, days (median) & $2(1,3)$ & $2(1,4)$ & 0.82 \\
\hline Hospital LOS after randomization, days (median) & $6.5(4.5,8.0)$ & $6.0(5.0,9.0)$ & 0.49 \\
\hline \multicolumn{4}{|l|}{ Complications during hospital admission } \\
\hline Reintubation, n (\%) & $2(7)$ & $1(3)$ & 0.59 \\
\hline Readmission to ICU, n (\%) & 0 & 0 & \\
\hline Acute kidney injury, n (\%) & $2(7)$ & $5(16)$ & 0.43 \\
\hline Inotropes/vasopressor use >24 hours, n (\%) & $7(25)$ & $11(34)$ & 0.57 \\
\hline Myocardial infarction, $\mathrm{n}(\%)$ & 0 & 0 & \\
\hline Atrial fibrillation, $\mathrm{n}(\%)$ & $9(32)$ & $10(31)$ & $>0.99$ \\
\hline Pulmonary edema, n (\%) & $4(14)$ & $4(13)$ & $>0.99$ \\
\hline Heart failure, $\mathrm{n}(\%)$ & $2(7)$ & $2(6)$ & $>0.99$ \\
\hline Stroke, n (\%) & $1(4)$ & $2(6)$ & $>0.99$ \\
\hline
\end{tabular}




\begin{tabular}{lllr}
\hline & Placebo & Sitagliptin & P value \\
\hline Wound infection, $\mathrm{n}(\%)$ & 0 & 0 & \\
Surgical site bleeding, $\mathrm{n}(\%)$ & $2(7)$ & $2(6)$ & $>0.99$ \\
Surgical reintervention, $\mathrm{n}(\%)$ & $2(7)$ & $1(3)$ & 0.59 \\
\hline
\end{tabular}

Data are $\mathrm{n}(\%)$, mean $\pm \mathrm{SD}$, or median (IQR).

BG, blood glucose; CII, continuous insulin infusion; ICU, intensive care unit; LOS, length of stay; OR, operative room; SSI, sliding scale insulin.

(table 2). A small number of participants received steroids perioperatively $(16 \%$ vs $29 \%, \mathrm{p}=0.35)$ with no difference in glycemic control or insulin treatment. Both treatment groups had similar number of BG readings independent of the presence of hyperglycemia in the ICU or after transition to subcutaneous insulin (ICU readings: $15.4 \pm 18.1$ vs $11.7 \pm 7.3$; number of readings after transition: $20.0 \pm 11.2$ vs $20.4 \pm 8.5$, all $\mathrm{p}=\mathrm{NS}$ ) ${ }^{39}$

After the discontinuation of intravenous insulin and transition to subcutaneous insulin, the number of participants requiring subcutaneous insulin treatment was similar in both groups (16\% vs $18 \%, \mathrm{p}>0.99)$. The use of supplements or correctional insulin was also similar in both groups $(2.4 \pm 0.5 \mathrm{IU} /$ day in sitagliptin vs $2.4 \pm 0.9 \mathrm{IU} /$ day in placebo, $\mathrm{p}=0.70$ ) (table 2 ).

There were no differences in the mean BG during the operating room stay $(136 \pm 25 \mathrm{mg} / \mathrm{dL}$ vs $143 \pm 18 \mathrm{mg}$ / $\mathrm{dL})$, ICU stay $(137 \pm 16 \mathrm{mg} / \mathrm{dL}$ vs $138 \pm 25 \mathrm{mg} / \mathrm{dL})$, or after transition $(123 \pm 13 \mathrm{mg} / \mathrm{dL}$ vs $124 \pm 16 \mathrm{mg} / \mathrm{dL})$ in the sitagliptin group compared with placebo (all $\mathrm{p}=\mathrm{NS}$ ). The duration of intravenous insulin infusion was 17 (IQR 9, 80 ) hours in the control group and 12 (IQR 5, 88) hours in the sitagliptin group $(\mathrm{p}=0.57)$. In addition, there were no differences in the rate of hypoglycemia or in mean daily glucose during the hospital stay between treatment groups.

Finally, we found no differences in the ICU or hospital LOS, duration of surgery, need for vasopressors, complications, surgical reinterventions or readmissions after hospital discharge between treatment groups. During the 30-day follow-up after hospital discharge, visits to the emergency room were similar in both groups $(6 \%$ in the sitagliptin group vs $4 \%$ in the placebo, p $>0.99$ ) (table 3 ).

Table 3 Complication outcomes up to 30 days after hospital discharge

\begin{tabular}{|c|c|c|c|}
\hline & Placebo & Sitagliptin & $P$ value \\
\hline Participants (n) & 28 & 32 & \\
\hline Emergency room visits & $1(4)$ & $2(6)$ & $>0.99$ \\
\hline $\begin{array}{l}\text { Readmissions due to wound } \\
\text { infection }\end{array}$ & $1(4)$ & $1(3)$ & $>0.99$ \\
\hline $\begin{array}{l}\text { Readmission due to other } \\
\text { causes }\end{array}$ & 0 & $3(9)$ & 0.24 \\
\hline $\begin{array}{l}\text { Infections not requiring } \\
\text { readmission }\end{array}$ & $1(4)$ & $0(0)$ & 0.47 \\
\hline
\end{tabular}

Data are $n(\%)$.

\section{DISCUSSION}

In this pilot, randomized, double-blinded, placebo-controlled trial, we explored whether the use of sitagliptin could prevent stress-induced hyperglycemia and the need for insulin treatment in patients without diabetes undergoing CABG. Our results indicate that the use of sitagliptin, starting before surgery and continued during the hospital stay, did not reduce the frequency of stress hyperglycemia compared with placebo $(22 \%$ vs $21 \%$, $\mathrm{p}>0.99$ ) or the need for insulin therapy in the ICU or during the hospital stay.

The results of recent observational and randomized controlled studies have shown that the development of stress hyperglycemia after cardiac surgery is associated with higher rates of hospital complications, longer hospital stay, higher healthcare resource utilization, and a greater number of hospital complications. ${ }^{18} 1940$ As observed in this cohort, stress hyperglycemia (BG $>140 \mathrm{mg} / \mathrm{dL}$ ) after CABG surgery is reported in $\sim 70 \%$ of patients without $\mathrm{DM}^{1-3}$ and represents an independent risk factor of poor outcome compared with patients with normoglycemia $^{41}$ and in patients with known diabetes. ${ }^{18}{ }^{19}$ Despite ongoing debate about the optimal glucose target, there is strong agreement that improved glycemic control reduces perioperative complications in patients with DM $^{28} 2942$ and with stress hyperglycemia. ${ }^{43}$ Several studies have shown that treatment of stress hyperglycemia results in significant reductions of perioperative complications and mortality. ${ }^{26} 28{ }^{43}$ In the recent GLUCO-CABG trial ${ }^{38}$ we reported that intensive insulin therapy to maintain a BG between 100 and $140 \mathrm{mg} / \mathrm{dL}$ in subjects without diabetes resulted in a significant reduction in perioperative complication compared with BG target between 141 and $180 \mathrm{mg} / \mathrm{dL}$ after CABG surgery. Similarly, a subgroup analysis by van den Berghe $e t a t^{43}$ of surgical ICU patients reported that intensive insulin therapy effectively reduced mortality in patients without a history of diabetes, but did not improve outcomes in patients with diabetes. These results suggest that the development of stress hyperglycemia is associated with poor outcomes in surgical patients and that improvement in glycemic control may reduce complications during the perioperative period. In this pilot study, the use of a DPP-4 inhibitor did not contribute to improving glycemic control in patients with stress hyperglycemia.

Clinical guidelines from professional organizations recommend the use of insulin to manage stress 
hyperglycemia in cardiac surgery patients. ${ }^{23} 2444$ Although effective in improving glycemic control, ${ }^{27-29}$ its use is labor intensive and is associated with higher risk of hypoglycemia. ${ }^{30-33}$ Hypoglycemia after cardiac surgery, as hyperglycemia, has been found to be an independent factor for increased risk of complications, longer length of hospital stay, and increased mortality. ${ }^{45-47}$ The increased risk of iatrogenic hypoglycemia with insulin therapy has triggered the search of alternative approaches and treatment regimens. Recently, several randomized controlled studies have reported that the treatment with DPP-4 inhibitors results in similar improvement in glycemic control than insulin therapy, but with lower risk of hypoglycemia, in non-critically ill hospitalized patients with type 2 diabetes and mild to moderate hyperglycemia. ${ }^{348}$ Thus, we tested if stress hyperglycemia could be prevented with the use of a DPP-4 inhibitor, which could facilitate the management of patients after cardiac surgery. Unfortunately, our results indicate that treatment with sitagliptin was unsuccessful in preventing stress hyperglycemia after cardiac surgery. Among several causes, it could be possible that the time of administration of sitagliptin (24hours prior to surgery) was not early enough to prevent stress hyperglycemia. One potential explanation could be that patients were kept NPO (Nil per Os) during the perioperative period. Native glucagon-like peptide-1 (GLP-1) is secreted in response to food intake, thus perhaps inhibition of the DPP-4 enzyme may not necessarily lead to a significant increase of circulating GLP-1 in these patients as compared with patients who are tolerating oral intake. ${ }^{49}$ We could also speculate that the glycemic lowering effect of sitagliptin, an oral DPP-4 inhibitor, may not be potent enough to compensate for the stress hyperglycemic response. It is possible that the perioperative use of GLP-1 could achieve better glycemic control avoiding the need for insulin therapy after surgery. ${ }^{44} \mathrm{We}$ did observe lower insulin dose requirements and duration of insulin infusion among patients with hyperglycemia exposed to sitagliptin, which may shorten ICU stay for a patient and decrease the nursing effort spent on glycemic control.

We acknowledge several limitations in this trial, including the small number of randomized participants. This pilot study intended to generate preliminary estimates and to assess feasibility of a preoperative intervention to prevent stress hyperglycemia in patients without history of DM. We did observe minor differences in glucose levels before surgery and total insulin dose in the ICU among patients exposed to sitagliptin. These differences, however, are unlikely to be clinically significant. Our preliminary results do not justify the conduction of a larger clinical trial in patients without diabetes.

In summary, our findings indicate that the use of sitagliptin was well tolerated, but did not reduce the frequency of stress hyperglycemia or prevented the need for insulin therapy during the perioperative period after cardiac surgery.
Author affiliations

${ }^{1}$ Medicine, Emory University School of Medicine, Atlanta, Georgia, USA ${ }^{2}$ Biostatitics, Rollins School of Public Health, Atlanta, Georgia, USA

${ }^{3}$ Thoracic Surgery, Emory University School of Medicine, Atlanta, Georgia, USA

Acknowledgements This investigator-initiated study was supported by a clinical research grant from the Jacobs Research Foundation and Merck who provided sitagliptin and placebo medications.

Collaborators Katherine Carssow, N Renee Cook, Michele Fielding, Sonya Mathewson and Maria A Urrutia. (SITA-CABG Collaborators)

Contributors GU is the guarantor of this work and, as such, had full access to all the data in the study and takes responsibility for the integrity of the data and the accuracy of the data analysis. GU wrote the initial research proposal. SC, KT, and GU wrote the manuscript. FJP, RJG, PV, SJ, MH, RAG, and VHT reviewed/edited the research proposal and manuscript and contributed to the discussion. LP conducted the statistical analysis.

Funding GU is partly supported by research grants from the NIH/NATS (UL1 TR002378) from the Clinical and Translational Science Award program, and from $\mathrm{NIH}$ and National Center for Research Resources (1P30DK111024-01). FJP and PV are supported by NIH grants 1K23GM128221-01A1 and 3K12HD085850-03S1 respectively. GU has also received unrestricted research support for inpatient studies (to Emory University) from Merck, Novo Nordisk, AstraZeneca, Boehringer Ingelheim, and Sanofi. FJP received research support and consulting fees from Merck. FJP has received consulting fees from Boehringer Ingelheim, Lilly, and AstraZeneca. PV has received consulting fees from Merck and Boehringer Ingelheim. RJG has received unrestricted research support for research studies (to Emory University) from Novo Nordisk and consulting fees from Abbott, Sanofi, and Novo Nordisk.

Disclaimer The supporters of the study were not involved in the study design, data collection, analysis or interpretation of the results, or preparation of the manuscript.

Competing interests None declared.

Patient consent for publication Not required.

Ethics approval The study protocol and consent were approved by the Emory University Institutional Review Board.

Provenance and peer review Not commissioned; externally peer reviewed.

Data availlability statement Data are available upon reasonable request.

Open access This is an open access article distributed in accordance with the Creative Commons Attribution Non Commercial (CC BY-NC 4.0) license, which permits others to distribute, remix, adapt, build upon this work non-commercially, and license their derivative works on different terms, provided the original work is properly cited, appropriate credit is given, any changes made indicated, and the use is non-commercial. See: http://creativecommons.org/licenses/by-nc/4.0/.

\section{REFERENCES}

1. Schmeltz LR, DeSantis AJ, Thiyagarajan V, et al. Reduction of surgical mortality and morbidity in diabetic patients undergoing cardiac surgery with a combined intravenous and subcutaneous insulin glucose management strategy. Diabetes Care 2007;30:823-8.

2. McAlister FA, Man J, Bistritz L, et al. Diabetes and coronary artery bypass surgery: an examination of perioperative glycemic control and outcomes. Diabetes Care 2003;26:1518-24.

3. Carvalho G, Moore A, Qizilbash B, et al. Maintenance of normoglycemia during cardiac surgery. Anesth Analg 2004:99:319-24.

4. Weintraub WS, Stein B, Kosinski A, et al. Outcome of coronary bypass surgery versus coronary angioplasty in diabetic patients with multivessel coronary artery disease. J Am Coll Cardiol 1998;31:10-19.

5. Furnary AP, Zerr KJ, Grunkemeier GL, et al. Continuous intravenous insulin infusion reduces the incidence of deep sternal wound infection in diabetic patients after cardiac surgical procedures. Ann Thorac Surg 1999;67:352-60.

6. Davis G, Fayfman M, Reyes-Umpierrez D, et al. Stress hyperglycemia in general surgery: why should we care? J Diabetes Complications 2018;32:305-9.

7. Carson JL, Scholz PM, Chen AY, et al. Diabetes mellitus increases short-term mortality and morbidity in patients undergoing coronary artery bypass graft surgery. J Am Coll Cardiol 2002;40:418-23. 
8. Furnary AP, Gao G, Grunkemeier GL, et al. Continuous insulin infusion reduces mortality in patients with diabetes undergoing coronary artery bypass grafting. J Thorac Cardiovasc Surg 2003:125:1007-21.

9. Bucerius J, Gummert JF, Borger MA, et al. Stroke after cardiac surgery: a risk factor analysis of 16,184 consecutive adult patients. Ann Thorac Surg 2003;75:472-8.

10. Thourani VH, Weintraub WS, Stein B, et al. Influence of diabetes mellitus on early and late outcome after coronary artery bypass grafting. Ann Thorac Surg 1999;67:1045-52.

11. Risum ø, Abdelnoor M, Svennevig JL, et al. Diabetes mellitus and morbidity and mortality risks after coronary artery bypass surgery. Scand J Thorac Cardiovasc Surg 1996;30:71-5.

12. Guvener M, Pasaoglu I, Demircin M, et al. Perioperative hyperglycemia is a strong correlate of postoperative infection in type II diabetic patients after coronary artery bypass grafting. Endocr $J$ 2002;49:531-7.

13. Rehman H-ur, Mohammed K. Perioperative management of diabetic patients. Curr Surg 2003;60:607-11.

14. Farrokhi F, Smiley D, Umpierrez GE. Glycemic control in nondiabetic critically ill patients. Best Pract Res Clin Endocrinol Metab 2011;25:813-24.

15. Godinjak A, Iglica A, Burekovic A, et al. Hyperglycemia in critically ill patients: management and prognosis. Med Arh 2015;69:157-60.

16. Kwon S, Thompson R, Dellinger $P$, et al. Importance of perioperative glycemic control in general surgery: a report from the surgical care and outcomes assessment program. Ann Surg 2013;257:8-14.

17. Umpierrez GE, Kitabchi AE. ICU care for patients with diabetes. Curr Opin Endocrinol Diabetes 2004;11:75-81.

18. Kotagal M, Symons RG, Hirsch IB, et al. Perioperative hyperglycemia and risk of adverse events among patients with and without diabetes. Ann Surg 2015;261:97-103.

19. Székely A, Levin J, Miao Y, et al. Impact of hyperglycemia on perioperative mortality after coronary artery bypass graft surgery. $J$ Thorac Cardiovasc Surg 2011;142:430-7.

20. Falciglia M, Freyberg RW, Almenoff PL, et al. Hyperglycemia-related mortality in critically ill patients varies with admission diagnosis*. Crit Care Med 2009;37:3001-9.

21. Mendez CE, Mok K-T, Ata A, et al. Increased glycemic variability is independently associated with length of stay and mortality in noncritically ill hospitalized patients. Diabetes Care 2013;36:4091-7.

22. Frisch A, Chandra P, Smiley D, et al. Prevalence and clinical outcome of hyperglycemia in the perioperative period in noncardiac surgery. Diabetes Care 2010;33:1783-8.

23. Moghissi ES, Korytkowski MT, DiNardo M, et al. American association of clinical endocrinologists and American diabetes association consensus statement on inpatient glycemic control. Diabetes Care 2009;32:1119-31.

24. Schnipper JL, Magee M, Larsen K, et al. Society of hospital medicine glycemic control Task force summary: practical recommendations for assessing the impact of glycemic control efforts. J Hosp Med 2008;3(S5):66-75.

25. Seley JJ, D'Hondt N, Longo R, et al. Position statement: inpatient glycemic control. Diabetes Educator 2009;35(Suppl 3):65-9.

26. Umpierrez GE, Hellman R, Korytkowski MT, et al. Management of hyperglycemia in hospitalized patients in non-critical care setting: an endocrine Society clinical practice guideline. J Clin Endocrinol Metab 2012;97:16-38.

27. Van den Berghe G, Wilmer A, Hermans G, et al. Intensive insulin therapy in the medical ICU. N Engl J Med 2006;354:449-61.

28. van den Berghe $G$, Wouters $P$, Weekers $F$, et al. Intensive insulin therapy in critically ill patients. N Engl J Med 2001;345:1359-67.

29. Kitabchi $A E$, Freire $A X$, Umpierrez GE. Evidence for strict inpatient blood glucose control: time to revise glycemic goals in hospitalized patients. Metabolism 2008;57:116-20.

30. Brunkhorst FM, Engel C, Bloos F, et al. Intensive insulin therapy and pentastarch resuscitation in severe sepsis. $N$ Engl J Med 2008;358:125-39
31. De La Rosa GD, Donado JH, Restrepo AH, et al. Strict glycemic control in patients hospitalized in a mixed medical and surgical intensive care unit: a randomized clinical trial. Crit Care 2008;12.

32. Finfer S, Chittock DR, Su SY-S, et al. Intensive versus conventional glucose control in critically ill patients. N Engl J Med 2009;360:1283-97.

33. Preiser J-C, Brunkhorst F. Tight glucose control and hypoglycemia Crit Care Med 2008;36:1391.

34. Pasquel FJ, Gianchandani R, Rubin DJ, et al. Efficacy of sitagliptin for the hospital management of general medicine and surgery patients with type 2 diabetes (Sita-Hospital): a multicentre, prospective, open-label, non-inferiority randomised trial. Lancet Diabetes Endocrinol 2017;5:125-33.

35. American Diabetes Association. 2. Classification and Diagnosis of Diabetes: Standards of Medical Care in Diabetes-2019. Diabetes Care 2019;42(Suppl 1):S13-28.

36. Galindo RJ, Fayfman M, Umpierrez GE. Perioperative management of hyperglycemia and diabetes in cardiac surgery patients. Endocrinol Metab Clin North Am 2018;47:203-22.

37. Umpierrez GE, Smiley D, Hermayer K, et al. Randomized study comparing a Basal-bolus with a basal plus correction insulin regimen for the hospital management of medical and surgical patients with type 2 diabetes: basal plus trial. Diabetes Care 2013;36:2169-74.

38. Umpierrez G, Cardona S, Pasquel F, et al. Randomized controlled trial of intensive versus conservative glucose control in patients undergoing coronary artery bypass graft surgery: GLUCO-CABG trial. Diabetes Care 2015;38:1665-72.

39. Jones CE, Graham LA, Morris MS, et al. Association Between Preoperative Hemoglobin A1c Levels, Postoperative Hyperglycemia, and Readmissions Following Gastrointestinal Surgery. JAMA Surg 2017;152:1031-8.

40. Ascione R, Rogers CA, Rajakaruna $C$, et al. Inadequate blood glucose control is associated with in-hospital mortality and morbidity in diabetic and nondiabetic patients undergoing cardiac surgery. Circulation 2008;118:113-23.

41. Umpierrez GE, Isaacs SD, Bazargan N, et al. Hyperglycemia: an independent marker of in-hospital mortality in patients with undiagnosed diabetes. J Clin Endocrinol Metab 2002;87:978-82.

42. Lazar HL, Chipkin SR, Fitzgerald CA, et al. Tight glycemic control in diabetic coronary artery bypass graft patients improves perioperative outcomes and decreases recurrent ischemic events. Circulation 2004:109:1497-502.

43. Van den Berghe G, Wouters PJ, Kesteloot K, et al. Analysis of healthcare resource utilization with intensive insulin therapy in critically ill patients*. Crit Care Med 2006;34:612-6.

44. Sokos GG, Bolukoglu H, German J, et al. Effect of glucagon-like peptide-1 (GLP-1) on glycemic control and left ventricular function in patients undergoing coronary artery bypass grafting. Am J Cardiol 2007;100:824-9.

45. Stamou SC, Nussbaum M, Carew JD, et al. Hypoglycemia with intensive insulin therapy after cardiac surgery: predisposing factors and association with mortality. J Thorac Cardiovasc Surg 2011;142:166-73.

46. D'Ancona G, Bertuzzi F, Sacchi L, et al. latrogenic hypoglycemia secondary to tight glucose control is an independent determinant for mortality and cardiac morbidity. Eur J Cardiothorac Surg 2011:40:360-6.

47. Finfer S, Liu B, Chittock DR, et al. Hypoglycemia and risk of death in critically ill patients. N Engl J Med 2012;367:1108-18.

48. Umpierrez GE, Gianchandani R, Smiley D, et al. Safety and efficacy of sitagliptin therapy for the inpatient management of general medicine and surgery patients with type 2 diabetes: a pilot, randomized, controlled study. Diabetes Care 2013;36:3430-5

49. Januvia package insert, 2018, Merck. Available: https://www.merck. com/product/usa/pi_circulars/j/januvia/januvia_pi.pdf 